\title{
Treatment of petroleum refinery wastewater by physicochemical methods
}

\author{
Svetlana Zueva ${ }^{1,2, *}$, Valentina Corradini ${ }^{1}$, Elena Ruduka ${ }^{2}$, and Francesco Veglio ${ }^{1}$ \\ ${ }^{1}$ University of L'Aquila, Department of Industrial and Information Engineering and Economics, 67100 L'Aquila, Italy \\ ${ }^{2}$ Voronezh State University of Engineering Technologies, Department of Ecology and Chemical Technology, 39417, Voronezh, Russia
}

\begin{abstract}
The main objective of this work was to improve the technological scheme of oil refinery wastewater treatment. Replacment of the expensive filter section in a refinery plant by coagulation in order to increase effectiveness of the process at lower cost was investigated. This research has proven that $\mathrm{Ca}(\mathrm{OH}) 2$ and $\mathrm{Al} 2(\mathrm{SO} 4) 3$ were effective in treatment of oil wastewater. Central Composite Design was applied to two factors, the Al2(SO4)3 dosage and $\mathrm{pH}$. Under optimum conditions effect of removal of Turbidity did reach $100 \%$, Total hydrocarbons $90 \%$ and COD $70 \%$. Concentration of Total hydrocarbons in wastewater after treatment were below Limits for sewerage. Prevailing mechanism for coagulation was charge neutralization, associated with deposition of positively charged aluminum hydroxide onto negatively charged particles. Applying of cogulation will let significantly reduce operating expenses up to 5,436.35 $€ /$ year, at the same efficiency, due to replacing expensive filtration processes with cost of $102,600.00$ $€ /$ year.
\end{abstract}

\section{Introduction}

Industrial wastewater treatment is important study area in environmental engineering. According to the oil and gas $(\mathrm{O} \& \mathrm{G})$ statistics report, the energy-related water consumption during refining and petrochemical processing in 2018 is estimated at approximately $3.95 \times$ $107 \mathrm{~m}^{3} /$ day $(\sim 15 \%$ of the world's water) [1]. Petroleum processing wastewaters contains various organic and inorganic components that need to be treated before they can be discharged to any receiving waters [2, 3]. Wastewater is changeable and is a complex mixture with a high content of suspended solids, chemical oxygen demand (COD), heavy metals and certain content of hydrocarbons, depending on the plant configuration, operation procedures and type of oil being processed [4]. Due to the presents in the petroleum wastewater high concentration of polycyclic aromatics, it is considered as hazardous waste [5].

The treatment of wastewaters from oil refineries and petrochemical plants mostly apply primary and secondary treatments to separate the gross amount of oil and suspended solids [6]. In general, the treatment techniques can be classified into two main routes, physical (e.g., skimmer tank, American Petroleum Institute (API), and filtration) and reactive methods (e.g., flocculation/coagulation chemicals or biological remediation).

Microfiltration (MF) and ultrafiltration (UF) are applicable for pretreatment before the wastewater passes through, for example, reverse osmosis (RO) process for reusing purposes [7]. However, these conventional flotation techniques are not satisfactory for removing emulsified oils without chemical pre-treatment [8].

Chemical pre-treatment of oil-water, by acidification with coagulation, is based on the addition of chemicals that destroy the protective action of the emulsifying agent, overcoming the repulsive effects of the electrical double layers to allow finely-sized oil droplets to form larger droplets through coalescence $[9,10]$.

Coagulation is effective for removing high concentration organic pollutants and heavy metals in water and wastewater $[11,12,13]$. The most widely used coagulants are iron and aluminum salts $[14,15]$. These coagulants promote particle agglomeration by reducing the electrostatic particle surface charges in the acidic $\mathrm{pH}$ region prominently where hydrolyzed metal species are abundant [16]. This mechanism is usually combined with metal hydroxide precipitation and particle aggregation.

This paper investigated ways to change the expensive filter section in a refinery plant, Algeria (Figure 1) on coagulation in order to increase effectiveness of the process at lower cost during treatment of petroleum industry wastewater.

\section{Materials and Methods}

All experimental tests described in this chapter were performed with sample of wastewater collected after the Skimmer section in the Centre Treatment Oil ROM, Hassi Messaoud, Algeria (Figure 1).

Hydrated lime (calcium hydroxide) $10 \%(\mathrm{w} / \mathrm{v})$ and Aluminum Sulfate $20 \% \mathrm{w} / \mathrm{v}$ were used for the coagulation tests. Chemical properties of the samples

\footnotetext{
* Corresponding author: svetlana.zueva $@$ graduate.univaq.it
} 


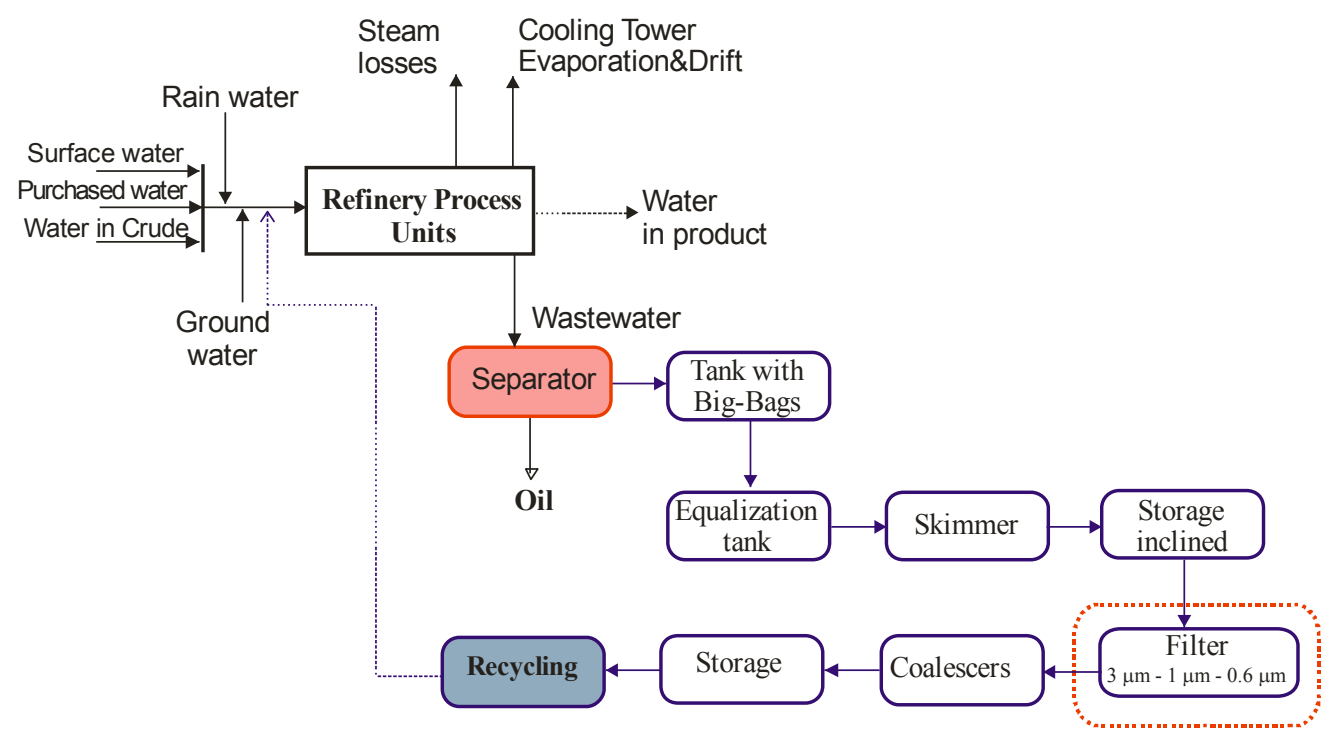

Fig. 1. The block diagram of the wastewater treatment process produced in the Centre Treatment Oil ROM, Hassi Messaoud, Algeria.

were determined by X-ray fluorescence (Spectro XEPOS 2000) using the instrument software. Sulphate and COD were measured with Dr. Lange's kit, cuvette-test LCK 153 and LCK 114A.

The water quality of the TS, TSS, TDS were measured by the standard methods. Samples collected (as described below) were analyzed for total solids (TS), total dissolved solids (TDS), and total suspended solids (TSS) using a modified version of Standard Method 2540 for solids determinations within the water and wastewater industry [13].

Measurements of turbidity were taken after the mixture settled for 10 minutes. The optical density (D) was measured at a fixed wavelength of $500 \mathrm{~nm}$ using a UV-visible spectrophotometer.

\section{Experimental Procedures}

In the present study, treatment of wastewater was conducted by a coagulation-flocculation process and the treatment efficiency was assessed in terms of chemical oxygen demand (COD), SST, SDT and turbidity values. Aeration process was applied to investigate its potential for effective post-treatment of the coagulationflocculation effluent.

The study consisted of three sets of experiments

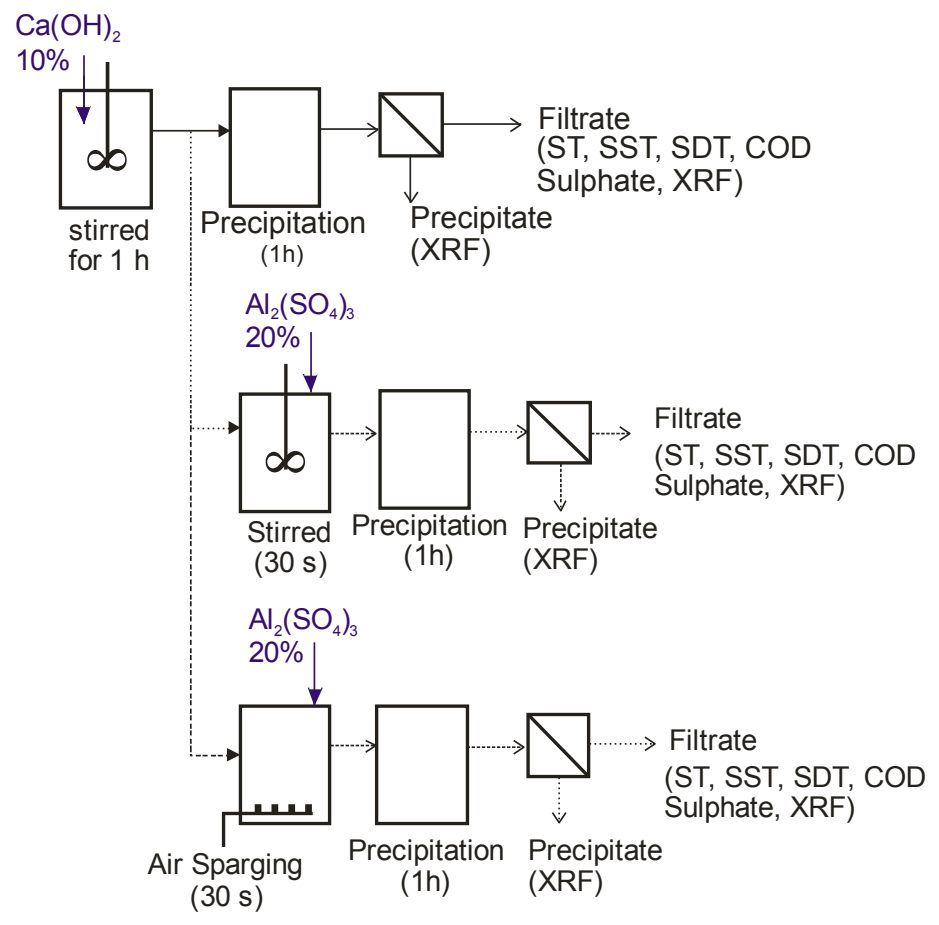

Fig. 2. The block diagram of studied wastewater treatment process. 
Table 1. Wastewater parameters before and after treatment with lime.

\begin{tabular}{|c|c|c|c|c|c|c|}
\hline $\mathbf{C a}(\mathbf{O H})_{2}, \mathbf{g} / \mathbf{L}$ & $\mathbf{p H}$ & $\mathbf{S D T}, \mathbf{g} / \mathbf{L}$ & $\mathbf{S S T}, \mathbf{g} / \mathbf{L}$ & $\mathbf{S O}_{\mathbf{4}}{ }^{2-}, \mathbf{g} / \mathbf{L}$ & Turbidity, NTU & $\mathbf{C O D}, \mathbf{g} / \mathbf{L}$ \\
\hline 0 & 1.9 & 374.29 & 0.463 & 0.198 & 0.62 & 2.15 \\
\hline 0.00026 & 6.5 & 350.56 & 28.029 & 0.286 & 0.28 & 1.97 \\
\hline 0.00080 & 8.0 & 347.74 & 32.125 & 0.259 & 0.20 & 1.86 \\
\hline 0.01900 & 9.5 & 272.00 & 77.491 & 0.931 & 0.02 & 1.65 \\
\hline
\end{tabular}

(Figure 2). The first set was used to study the effect of hydrated lime as coagulant on the wastewater treatment efficiency. The second set of experiments was used to determine the effect of the addition Aluminum Sulfate as coagulant aid (CA). The third set of experiments was used to determine the effect of air injection.

\section{Results and Discussion}

\subsection{The Effect of Hydrated Lime}

The effect of hydrated lime as coagulant on the wastewater treatment efficiency was studied. Table 1 compares main controlled wastewater parameters before and after treatment with lime.

It could be seen, that in interval of $\mathrm{pH}$ from 1.9 up to 9.40 wastewater did change the color from orange first to light-brown and then to green and could be related to following reaction:

$$
\mathrm{Cl}^{-}+\mathrm{Ca}(\mathrm{OH})_{2}=\mathrm{CaOCl}_{2}+\mathrm{H} 2 \mathrm{O}
$$

$$
\begin{gathered}
\mathrm{Fe}^{3+}+3 \mathrm{Ca}(\mathrm{OH})_{2}=2 \mathrm{Fe}(\mathrm{OH})_{3} \downarrow \text { (brown flocks }+\mathrm{Ca}^{2+} \\
\mathrm{Fe}^{2+}+3 \mathrm{Ca}(\mathrm{OH})_{2}=\mathrm{Fe}(\mathrm{OH})_{2} \downarrow \text { (gray-green flocks) }+\mathrm{Ca}^{2+}
\end{gathered}
$$

Based on this we can suggest that wastewater after treatment with lime we have a mixture of calcium hypochlorite $\left(\mathrm{Ca}(\mathrm{OCl})_{2}\right)$ and the basic chloride $\mathrm{CaCl}_{2}$, $\mathrm{H}_{2} \mathrm{O}$ with some slaked lime, $\mathrm{Ca}(\mathrm{OH})_{2}$.

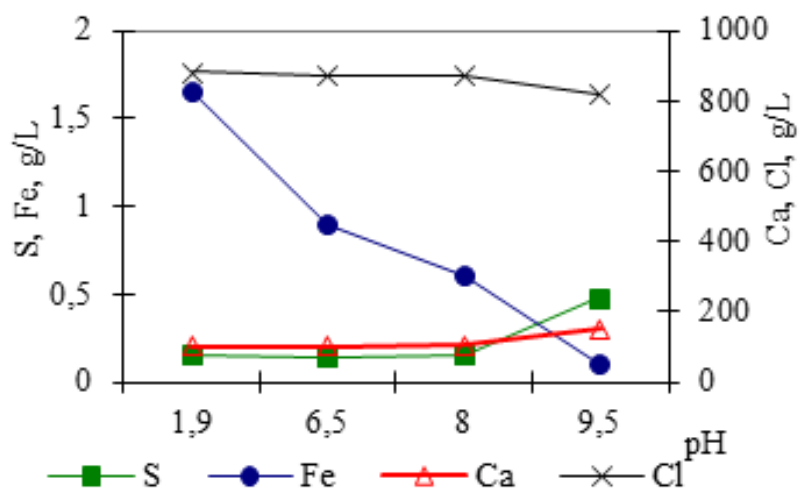

(a)
Figure 3 shows effect of $\mathrm{pH}$ on concentration of elements in solid and liquid phase respectively.

As can be seen from the Table 1 with increasing amount of lime increases SST, decrease SDT, COD and turbidity. At $\mathrm{pH}=9.5$, the best results are obtained on $\mathrm{Fe}$ salts and turbidity removal, but concentration of sulfates in liquid at high $\mathrm{pH}$ value significantly increases in 4 times due to re-dissolution of residue, high consumption of reagent is required and process operates at corrosive media. At $\mathrm{pH}=8.0$ positive effect of lime treatment: precipitation of $\mathrm{Fe}$ salts, but no significant change in turbidity.

\subsection{The Effect of Aluminum Sulfate}

The application of aluminum sulfate in the presence of lime was also studied. To increase efficiency of the process wastewater, after adjustment of $\mathrm{pH}$ with lime, was treated with different dose of aluminum sulfate: $0.12,0.40$ and $0.68 \mathrm{mg} / \mathrm{L}$. Experiments were run during which aluminum sulfate was applied at an increasing concentration while the $\mathrm{pH}$ was maintained constant $(6.5,8.0$ and 9.5).

Figure 3 shows Turbidity removal efficiency depending on aluminum sulfate dosage at different $\mathrm{pH}$. Turbidity removal reached its peak $(99.8 \%)$ at $\mathrm{pH} 9.5$ for all dosage of aluminum sulfate.

In the aluminum sulfate treatment, once the emulsions were destabilized and reached the lowest turbidity values (optimum dose), further addition of aluminum sulfate did not destabilize the emulsions and

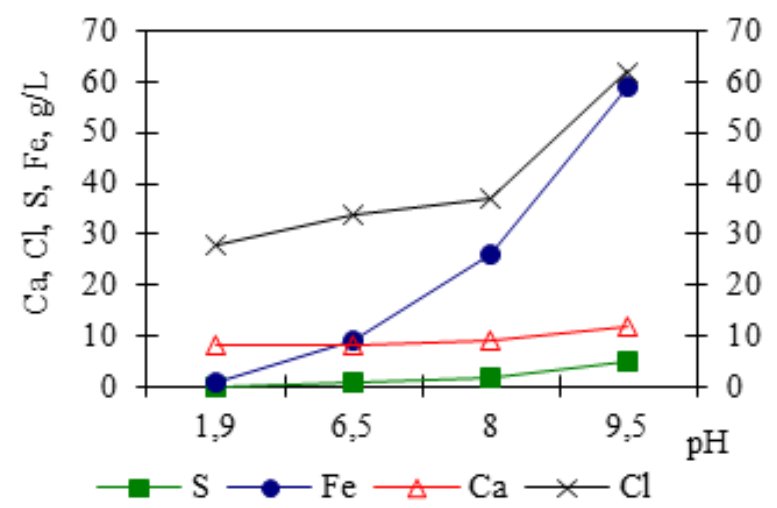

(b)

Fig. 3. Effect of $\mathrm{pH}$ on concentration of elements in solid (a) and liquid (b) phase. 


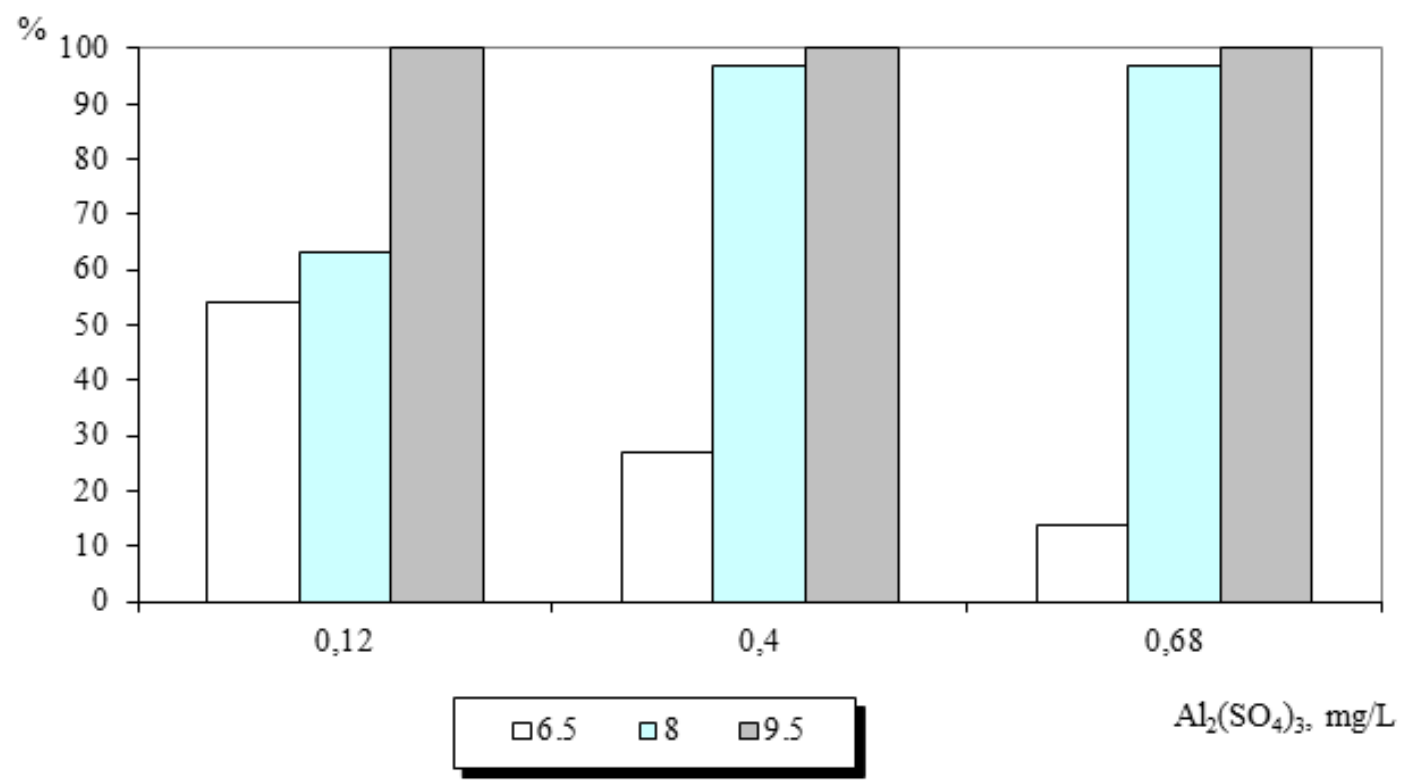

Fig. 3. Effect $\mathrm{Al} 2(\mathrm{SO} 4) 3$ dosage on removal turbidity at different $\mathrm{pH}$.

turbidity remained low.

At low $\mathrm{pH}$ only, $\mathrm{Al}^{3+}$ exists in a significant amount; when $\mathrm{pH}$ shifts to alkaline values hydrolysis is produced and aluminium hydroxide precipitates, although this occurs in a narrow range around $\mathrm{pH}$ 6.5. The $\mathrm{pH}$ increase result in dissolution of the precipitate previously formed by $\mathrm{Al}(\mathrm{OH})^{4-}$. The proposed coagulation mechanism, based on experimental results, can be explained by hydrolyzed metal ions destabilization model, in which electrostatic attraction, chemical forces and adsorption are all important.

Considering the relevance of $\mathrm{pH}$ on the hydrolysis products of aluminum sulfate, different experiments were designed to analyze $\mathrm{pH}$ effects. Coagulation experiments highlighted that a slight over-dosage of Aluminium Sulfate could impact efficiency in a negative manner. Therefore, in order to achieve optimum dosage of coagulant, Central Composite Design was applied to two factors, the $\mathrm{Al}_{2}\left(\mathrm{SO}_{4}\right)_{3}$ dosage and $\mathrm{pH}$. Variation intervals are shown in the Table 2.

Table 2. Wastewater parameters before and after treatment with lime.

\begin{tabular}{|c|c|c|c|}
\hline \multirow{2}{*}{ Factor name } & \multicolumn{3}{|c|}{ Variation interval } \\
\cline { 2 - 4 } & $\mathbf{- 1}$ & $\mathbf{0}$ & $\mathbf{+ 1}$ \\
\hline $\begin{array}{c}\mathrm{X}_{1}-\text { volume of coagulant } 20 \% \\
\mathrm{Al}_{2}\left(\mathrm{SO}_{4}\right)_{3}, \mathrm{ml} / 50 \mathrm{~mL} \text { of sample }\end{array}$ & 0.12 & 0.40 & 0.68 \\
\hline $\mathrm{X}_{2}-$ wastewater $\mathrm{pH}$, units & 6.5 & 8.0 & 9.5 \\
\hline
\end{tabular}

Table 3 summarizes the main properties of the wastewater before and after the different methods of treatment. $\mathrm{CCD}$ identified the following optimum parameters: $\mathrm{pH}=7.3$ and $\mathrm{Al}_{2}\left(\mathrm{SO}_{4}\right)_{3}$ dosage $0.43 \mathrm{mg} / \mathrm{L}$. For these parameters the $\left(\mathrm{SO}_{4}\right)^{2-}$ concentration in the solution after treatment will be $115 \mathrm{mg} / \mathrm{L}$ (instead of 198 $\mathrm{mg} / \mathrm{L}$ ). Farther increasing of $\mathrm{pH}$ value and coagulant dosage, result in increasing of residual sulfate's concentration up to $931 \mathrm{mg} / \mathrm{L}$.
To estimate economic efficiency of coagulation process were used the following formulas:

Total Cost $=$ Cost of Reagents + Operating Cost

Cost of Reagents $=$ Sum of Costs of All Reagents (5)

Operating Cost $=$ Cost of Water $(\mathrm{CW})+$ + Cost of Electrical Energy (CE)

Cost of Reagent $=$

Wastewater flow rate ${ }^{\bullet}$ Reagent Price ${ }^{`}$ Operating Days(7)

Cost of Water $=$ Water for Reagents $\cdot$ Water Price(8)

Cost of Electrical Energy =

Engine Power Compressor` Time`Electrical Energy (9)

Total Cost $=$ Price of filter

Number of filters ' Replacement frequency

Results of calculations shows that to filters replacement company spends 102,600.00 €/year. Applying of aluminum sulfate treatment will significantly reduce operating expenses to 5,436.35 $€ /$ year, at the same efficiency.

\section{Conclusions}

This research has proven that $\mathrm{A} 12(\mathrm{SO} 4) 3$ was effective in the oil wastewater treatment. Results of experiment identified optimum dosage of coagulant to get maximum sedimentation and removing dissolved and solid pollution and allow us to draw the following conclusions:

The process is more effective if staggered as follows:

i) neutralization with $\mathrm{Ca}(\mathrm{OH}) 2$

ii) coagulation with $\mathrm{Al} 2(\mathrm{SO} 4) 3$

iii) injection of air and sedimentation. 
Table 3. Properties of the wastewater before and after treatment.

\begin{tabular}{|c|c|c|c|c|}
\hline \multirow[b]{2}{*}{ Property } & \multirow{2}{*}{$\begin{array}{l}\text { Initial waste } \\
\text { water }\end{array}$} & \multicolumn{3}{|c|}{ After treatment } \\
\hline & & $\mathrm{Ca}(\mathrm{OH})_{2}$ & $\begin{array}{c}\mathrm{Ca}(\mathrm{OH})_{2}+ \\
\mathrm{Al}_{2}(\mathrm{SO})_{4}+\text { Stiring }\end{array}$ & $\begin{array}{c}\mathrm{Ca}(\mathrm{OH})_{2}+ \\
\mathrm{Al}_{2}(\mathrm{SO})_{4}+\mathrm{Air}\end{array}$ \\
\hline Turbidity (NTU) & 0.62 & 0.02 & 0.014 & 0.013 \\
\hline Total hydrocarbons (mg/L) & 93 & 24 & 18 & 9 \\
\hline $\operatorname{COD}(\mathrm{g} / \mathrm{L})$ & 2.15 & 1.86 & 1.65 & 0.71 \\
\hline $\mathrm{SST}(\mathrm{g} / \mathrm{L})$ & 0.46 & 32.13 & 21.39 & 20.56 \\
\hline $\operatorname{SDT}(g / L)$ & 374.28 & 347.74 & 348.16 & 304.12 \\
\hline $\mathrm{SO}_{4}{ }^{2-}(\mathrm{mg} / \mathrm{L})$ & 198.60 & 260.00 & 259.00 & 259.00 \\
\hline $\mathrm{S}(\mathrm{g} / \mathrm{L})$ & 0.037 & 0.037 & 0.036 & 0.036 \\
\hline $\mathrm{Cl}(\mathrm{g} / \mathrm{L})$ & 208.70 & 202.13 & 201.10 & 201.10 \\
\hline $\mathrm{Fe}(\mathrm{g} / \mathrm{L})$ & 0.39 & 0.15 & 0.14 & 0.14 \\
\hline $\mathrm{Ca}(\mathrm{g} / \mathrm{L})$ & 24.01 & 24.73 & 24.03 & 24.03 \\
\hline
\end{tabular}

Under these conditions, effect of removal of Turbidity was $100 \%$, Total hydrocarbons $90 \%$ and COD $70 \%$. Concentration of Total hydrocarbons in wastewater after treatment was below Limits for sewerage.

Mechanism for coagulation can be suggested, as charge neutralization is associated with deposition of positively charged aluminum hydroxide onto negatively charged particles.

Comparing the cost of coagulation and filtration processes, it is evident that to filters replacement company spends 102,600.00 €/year. Applying of aluminum sulfate treatment will significantly reduce operating expenses to $5,436.35 € /$ year, at the same efficiency.

\section{References}

[1] S.A. Younis, H.A. Maitlo, J. Lee, K.H. Kim, Adv. Colloid. Interfac. J., 275 (2019).

[2] D.A. Iljuboury, P. Palaniandy, H.B. Abdul Aziz, GlobalNEST J., 19, 3 (2017).

[3] Y. Mikhak, M.M.A. Torabi, A. Fouladitajar, Sustainable Water and Wastewater Processing, Chapter 3, Refinery and petrochemical wastewater treatment (2019).

[4] S. J. Kulkarni, A. K. Goswami, IJSRSET J, 1, 3 (2015).

[5] D.A. Aljuboury, P. Palaniandy, H.B. Abdul Aziz, S. Feroz, Global NEST J., 19, 3 (2017).

[6] B. Wang, W. Yi, G. Yingxin, Z. Guomao, Y. Min, W. Song, H. Jianying, Environ, Sci. Technol. J., 49 (2015).
[7] M.C. Vincent-Vela, S. Álvarez-Blanco, J. LoraGarcía, C. Carbonell-Alcaina, M. Sáez Muñoz, Desalination Water Treat. J., 55, 13 (2015).

[8] C. Wu, Y. Zhou, P. Wang, S. Guo, Bioresour. Technol. J., 194 (2015).

[9] B.K. Pramanik, L. Shu, V. Jegatheesan, A.M. Bhuiyan, J. Environ. Manage, 249 (2019).

[10] W. Chen, H. Zheng, H. Teng, PLoS One. J., 10, 9 (2015).

[11] Z. Daud, H. Awang, A.A. Latif, N. Nasir, M.B. Ridzuan, Z.Ahmad, Procedia Soc.Behav. Sci. J., 195 (2015).

[12] G. Di Bella, M. G. Giustra, G. Freni. Chem. Eng. J., 254 (2014).

[13] K. Lal, A. Garg, J. Environ. Chem. Eng., 7, 5 (2019).

[14] M. Umar, F. Roddick, L. Fan, Chem. Eng. J., 284 (2016).

[15] C.Y. Teh, P.M. Budiman, K.P.Y. Shak, T.Y. Wu, Ind. Eng. Chem. Res. J., 55, 16 (2016).

[16] Y. Sun, S. Zhou, S.-Y. Pan, S. Zhu, Y. Yu, H. Zheng, Chem. Eng. J., 385 (2019). 